\title{
Long-Term Oil Price Forecasts: A New Perspective on Oil and the Macroeconomy ${ }^{1}$
}

\author{
J. Isaac Miller ${ }^{2}$ and Shawn Ni \\ Department of Economics, University of Missouri \\ 118 Professional Building, Columbia, Missouri 65211, USA
}

\begin{abstract}
We examine how future real GDP growth relates to changes in the forecasted longterm average of discounted real oil prices and to changes in unanticipated fluctuations of real oil prices around the forecasts. Forecasts are conducted using a state-space oil market model, in which global real economic activity and real oil prices share a common stochastic trend. Changes in unanticipated fluctuations and changes in the forecasted longterm average of discounted real oil prices sum to real oil price changes. We find that these two components have distinctly different relationships with future real GDP growth. Positive and negative changes in the unanticipated fluctuations of real oil prices correlate with asymmetric responses of future real GDP growth. In comparison, changes in the forecasted long-term average are smaller in magnitude but are more influential on real GDP. Persistent upward revisions of forecasts in the 2000s had a substantial negative impact on real GDP growth, according to our estimates.
\end{abstract}

This version: October 13, 2010

JEL classification: E31, E32, Q43

Key words and phrases: oil price and the macroeconomy, oil market fundamental, oil price forecasts, Kalman filter

\footnotetext{
${ }^{1}$ The authors are grateful to Lutz Kilian for helpful discussions on this research. The authors appreciate useful feedback received from the editors, John Elder and Apostolos Serletis, two anonymous referees, Elizabeth B. Miller, and participants of the 2010 meeting of the Midwest Econometrics Group, the 2010 Missouri Economics Conference, and an MU economics department colloquium. The first author acknowledges financial support from the Economic Policy and Research Center at the University of Missouri.

${ }^{2}$ Correspondence: millerjisaac@missouri.edu, 573-882-7282(ph), 573-882-2697(fx).
} 


\section{Introduction}

Fluctuations in oil prices have long been considered a potentially important source of business cycles. A vast literature originating from papers by Hamilton (1983), Burbidge and Harrison (1984), and Gisser and Goodwin (1986) has utilized Vector AutoRegressions to examine how changes in oil prices relate to future changes in GDP. The empirical relationship between oil price movements and the macroeconomy is still a subject of debate, as evidenced by many recent papers on the subject. ${ }^{3}$ After the oil price collapse of 1986 failed to generate a boom as predicted by a symmetric model, many authors found estimates from simple VARs using oil price changes to be inadequate. On the other hand, they found those based on alternative measures of oil price movements to be more robust. Mork (1989) introduced a simple decomposition of oil price changes to allow for asymmetric responses of GDP growth to oil price increases and decreases. Following Mork's (1989) suggestion to model asymmetry, Lee et al. (1995) and Hamilton (1996, 2003) proposed using the scaled oil price increase/decrease (SOPI/D) and the net oil price increase/decrease (NOPI/D). ${ }^{4}$

A focal point of these VAR studies is the response of GDP growth to structural shocks to oil price changes or to functions of oil price changes. In VAR models, oil prices are predicted by recent oil prices and macro variables in the VAR. The impulse response of interest concerns the dynamics of output to unanticipated (structural) shocks in oil price changes. ${ }^{5}$

In this paper, we suggest an empirical approach to analyze the oil price-macroeconomy relationship that differs from the traditional emphasis on oil price shocks. We argue that changes in the forecasted long-term average of discounted real oil prices can be more influential on households' and firms' decisions than shocks to (functions of) real oil prices. (We use "average prices" and "averages of prices" interchangeably throughout the paper, in spite of a possible shade of connotational difference.) Consider two examples of why this is the case. First, because the average fuel price during the lifespan of transportation equipment determines user cost, a forecast of this average price is a key determinant of demand for oil-intensive transportation equipment, such as cars, trucks, and airplanes. ${ }^{6}$ Second,

\footnotetext{
${ }^{3}$ For analysis on whether oil shocks affect the macroeconomy through monetary policy, see Bernanke et al. (1997), Barksy and Kilian (2002, 2004), Hamilton and Herrera (2004), and Herrera and Pesavento (2009).

${ }^{4}$ For comprehensive analysis of the nonlinear relationship between GDP growth and oil price increase/decrease, see Mork et al. (1994), Hooker (1996), Balke et al. (2002), Jiménez-Rodríguez (2009), and Kilian and Vigfusson (2009). Several authors have focused on a structural interpretation of the changing correlation between oil price growth and GDP growth. Baumeister and Peersman (2008), Miller and Ratti (2009), Edelstein and Kilian (2009), Kilian and Park (2009), and Blanchard and Galí (2010) examine the changing correlation between economic outcomes and the real price of oil since the 1970s. Barksy and Kilian $(2002,2004)$ recognized the different effects of unanticipated supply and demand shocks to the oil market on macroeconomic indicators, and Kilian $(2008,2009)$ has recently used an oil market model to identify these shocks.

${ }^{5}$ When a VAR is based on more than one component of oil price changes, there needs to be a constraint that the components sum to the observed oil price change. In this case, the impulse responses are not well defined in a conventional VAR. Kilian and Vigfusson (2009) have recently noted other difficulties in using impulse response analysis with asymmetric responses to shocks to decomposed oil price changes.

${ }^{6}$ The Energy Information Administration (Oil Market Basics <http://www.eia.doe.gov/pub/oil_gas/ petroleum/analysis_publications/oil_market_basics/ $>$ ) estimates that about two-thirds of the end-use of oil in the US is for transportation.
} 
an increase in the value of imported oil induces a negative income effect. The permanent income hypothesis suggests that an increase in the expected long-term average real oil price induces a much larger decline in permanent income than would a temporary increase of the same size. Therefore, a much larger cut in consumption by rational consumers results. In this light, our approach filters the long-term information conveyed by real price changes as an approximation to economic agents' interpretations of these changes.

In order to distinguish the different effects on US real GDP growth, we decompose real oil price changes into two components. The first component is defined as updates in the forecast of long-term average prices and is estimated using an oil market model. We denote this component by $\Delta o^{F}$. The second component, denoted by $\Delta o^{U}$, is defined as changes in deviations of the oil price from these forecasts. We formally define the latter component at time $t$ by subtracting $\Delta o_{t}^{F}$ and a constant for discounting from the first difference of the log real oil price at time $t$. As this component is defined using a residual from the oil market model, we consider this to be an unanticipated component - hence the notation.

We propose a state-space model for the prediction of the long-term averages of future real oil price levels. In this model, real oil prices fluctuate around the combination of a time trend and an unobservable stochastic trend, a modelling strategy loosely based on suggestions of Hotelling (1931), Pindyck (1999), and Hamilton (2009). ${ }^{7}$ The stochastic trend captures uncertainty about the long-term average. We present empirical evidence that global real economic activity and real oil prices share a stochastic trend, after subtracting different linear trends. Hence, both past real oil prices and real global economic activity contain useful information for predicting future real oil prices. In this setting, the best forecast of the future average discounted price is the stochastic trend component, parsimoniously filtered using current and historical data on real oil prices and global real economic activity. According to our results, the multivariate state space specification compares favorably to several univariate state-space models and rule-of-thumb forecasting models when considering forecasts of averages over long horizons.

It is important to note that our estimates of changes in the forecasts rely on information in the levels of real oil prices. In contrast, the conventional VARs discussed above use changes in (real or nominal) oil prices.

Our empirical results can be summarized as follows. First, changes in the forecasted long-term average of discounted real oil prices, $\Delta o^{F}$, are much smaller in magnitude than changes in the fluctuations of real oil prices around these averages, $\Delta o^{U}$. On the other hand $\Delta o^{F}$ is more influential on US GDP growth than $\Delta o^{U}$. Focusing only on unanticipated real oil price shocks (e.g., Kilian, 2009) or only on large price changes (e.g., Hamilton, 1996, 2003) underestimates the effect of real oil price changes. While these authors provide important tools for analyzing the oil price-macroeconomy relationship, our approach is more inclusive. Conventional measures may explain the episodes of 1974, 1986, and 1991 well, but may not explain the lack of an oil-related recession following the 2003-07 oil price run-up. Blanchard and Galí (2010) noted a "lack of concurrent adverse shocks" during this period. Our results suggest that persistent upward revision of the forecasted long-term average real

\footnotetext{
${ }^{7}$ The linear trend is based on Hotelling's (1931) assumption that an arbitrage condition holds. Pindyck (1999) suggested allowing stochastic coefficients on the linear trend, and Hamilton (2009) suggested a stochastic trend. The approaches of stochastic trend and deterministic trend with stochastic coefficients are similar.
} 
oil price (rather than real oil price shocks) over this period had a substantial negative impact on real GDP growth. ${ }^{8}$

Second, we find that positive and negative changes in unanticipated real oil price fluctuations correlate with responses of future GDP growth that are asymmetric in sign, echoing the results of Mork (1989) for changes in oil prices themselves. Both increases and decreases in the unanticipated component are followed by decreases in real GDP growth. On the other hand, responses of real GDP growth to positive and negative changes in the forecasted average are symmetric in sign but have different magnitudes. Specifically, a $1 \%$ increase in the forecasted average - holding the other components constant and net of a linear upward trend - is correlated with a $0.11 \%$ cumulative decrease in future real GDP growth. On the other hand, a $1 \%$ decrease is correlated with a $0.07 \%$ cumulative increase in future real GDP growth. These results suggest that the main channels through which $\Delta o^{F}$ and $\Delta o^{U}$ affect economic activity are different. By using the first difference of real oil price (the sum of $\Delta o^{F}$ and $\Delta o^{U}$ ), a traditional VAR, or one modified for asymmetry, does not distinguish the differential effects of the two components.

The remainder of the paper is structured as follows. In the following section, we present the basic reduced-form model to estimate the impact of real oil price changes on US economic growth, and the oil market model used to identify the forecasted long-term average of discounted real oil prices. Section 3 contains our empirical results, and Section 4 concludes. Two brief appendices contain a discussion and comparison of alternative oil market models and a methodological description of our cumulative conditional response functions and counterfactual US GDP growth rates.

We note that both oil prices and GDP are measured in real terms throughout the paper. For ease of exposition, further references to GDP and oil prices should be taken to mean real GDP and real oil prices, unless otherwise specified.

\section{Oil Price Forecasts and Economic Growth}

Consider the US GDP equation of a standard bivariate reduced-form oil price-macroeconomy VAR, given by

$$
\Delta y_{t}=\delta+\sum_{k=1}^{p} \alpha_{k} \Delta y_{t-k}+\sum_{k=1}^{p} \pi_{k} \Delta o_{t-k}+\varepsilon_{t},
$$

which is similar to the GDP equation of Hamilton's (1983) basic model. In this model, $\left(y_{t}\right)$ is the log of real GDP and $\left(o_{t}\right)$ is the log of the real price of oil. To estimate this benchmark model, we regress US GDP growth on $p$ lags of itself and $p$ lags of the growth rate of oil prices, with $p=4$ in our empirical results.

Real oil price growth $\left(\Delta o_{t}\right)$ may be decomposed into updates of forecasted long-term averages of discounted oil prices $\left(\Delta o_{t}^{F}\right)$, a constant discounting term that we subsequently

\footnotetext{
${ }^{8}$ The sum of Kilian's (2009) three structural shocks appears to be positive during this period, a result which is numerically similar to $\Delta o^{F}$. This difference reflects only a minor difference of economic intuition. From Kilian's (2009) figures, the strongest driver of oil prices during this period appears to be aggregated demand shocks. Using our model, the strongest driver during this period is revisions in oil price forecasts, which are strongly correlated with the growth of global real economic activity. We believe that global demand is the channel of this correlation.
} 
denote by $\gamma_{o 2}$ to reflect the time trend from Hotelling's model, and changes in unanticipated deviations of the actual price from the forecasted averages $\left(\Delta o_{t}^{U}\right)$. Formally, $\Delta o_{t}=\gamma_{o 2}+$ $\Delta o_{t}^{F}+\Delta o_{t}^{U}$. Once these components are identified, then

$$
\Delta y_{t}=\delta^{*}+\sum_{k=1}^{p} \alpha_{k} \Delta y_{t-k}+\sum_{k=1}^{p} \pi_{k}^{F} \Delta o_{t-k}^{F}+\sum_{k=1}^{p} \pi_{k}^{U} \Delta o_{t-k}^{U}+\varepsilon_{t} .
$$

may be estimated, where $\delta^{*}$ differs from $\delta$ due to $\gamma_{o 2}$.

We use a separate oil market model to identify $\left(\Delta o_{t}^{F}\right)$, which we discuss below.

\subsection{Forecasts of Average Discounted Oil Prices}

A key empirical consideration is estimation not only of the change in the forecasted oil price from time $t-1$ to time $t$, but also of the change in the average price up to $N$ periods ahead, where $N$ reflects the lifespan of energy intensive goods. If we take literally Hotelling's (1931) hypothesis in the context of perfect competition, then an arbitrage condition holds so that the oil price growth rate is equal to a risk-free interest rate $\gamma_{o 2}$. The change in the forecasted average (log real) price would be simply $\gamma_{o 2}$.

Although Hamilton (2009) has recently suggested the importance of scarcity rents, making the linear trend feasible, he also found evidence for a unit root in oil prices. An appropriate model for such a forecast is

$$
o_{t}=\gamma_{o 1}+\gamma_{o 2} t+\beta_{o} z_{t}+\eta_{t},
$$

where $\left(z_{t}\right)$ is a latent stochastic trend of $\left(o_{t}\right)$ - i.e., $\left(z_{t}\right)$ is an unobserved random walk, $\gamma_{o 1}+\gamma_{o 2} t$ is a linear trend of $\left(o_{t}\right)$, and $\left(\eta_{t}\right)$ is stationary error. In Hotelling's model, $\gamma_{o 2}$ is an interest rate and $o_{t}-\gamma_{o 2} t$ is the discounted oil price. In this framework, $\left(o_{t}-\gamma_{o 1}-\gamma_{o 2} t\right)$ - rather than $\left(o_{t}\right)$ - is a driftless unit root process. $\left(o_{t}\right)$ itself has drift given by $\gamma_{o 2}$, and $\gamma_{o 1}$ captures its initial observation.

Using the conventional notation that $o_{s \mid t}$ denotes the expectation of $o_{s}$ conditional on the information set available at time $t$, the forecasted discounted $\log$ oil price at $t+j$ given information at $t$ is

$$
o_{t+j \mid t}-\gamma_{o 2}(t+j)=\gamma_{o 1}+\beta_{o} z_{t \mid t}+\eta_{t+j \mid t},
$$

where we use the result that $z_{t+j \mid t}$, a linear prediction of $z_{t+j}$ with information available at time $t$, equals $z_{t \mid t}$, following the assumption that $z_{t}$ is a random walk in the model. In the absence of serial correlation in $\left(\eta_{t}\right)$, the last term is zero. The average of forecasts up to $N$ periods ahead is

$$
\frac{1}{N} \sum_{j=1}^{N}\left(o_{t+j \mid t}-\gamma_{o 2}(t+j)\right)=\gamma_{o 1}+\beta_{o} z_{t \mid t}+\frac{1}{N} \sum_{j=1}^{N} \eta_{t+j \mid t}
$$

where $\frac{1}{N} \sum \eta_{t+j \mid t} \approx 0$ for a reasonably large forecast horizon $N$, even in the presence of weak serial correlation. 
We may also interpret an average of forecasts from a linear model, such as (4), as a forecast of an average. Now, the first difference of this forecast is given by

$$
\begin{aligned}
& \frac{1}{N} \sum_{j=1}^{N}\left(o_{t+j \mid t}-\gamma_{o 2}(t+j)\right)-\frac{1}{N} \sum_{j=1}^{N}\left(o_{t+j-1 \mid t-1}-\gamma_{o 2}(t+j-1)\right) \\
& =\beta_{o}\left(z_{t \mid t}-z_{t-1 \mid t-1}\right)+\frac{1}{N} \sum_{j=1}^{N}\left(\eta_{t+j \mid t}-\eta_{t+j-1 \mid t-1}\right),
\end{aligned}
$$

where the last term is approximately zero - with or without weak serial correlation. The above equation suggests we can estimate the change in the forecast of the average of discounted oil prices by

$$
\Delta o_{t}^{F}=\beta_{o}\left(z_{t \mid t}-z_{t-1 \mid t-1}\right) .
$$

To see how this leads to a decomposition of the first difference in oil price $\Delta o_{t}$, note from (3) that

$$
\Delta o_{t}=\gamma_{o 2}+\beta_{o} \Delta z_{t}+\Delta \eta_{t}
$$

This suggests a decomposition

$$
\Delta o_{t}=\gamma_{o 2}+\Delta o_{t}^{F}+\Delta o_{t}^{U}
$$

After subtracting the update in the expected long-term average of oil prices from the oil price change, the unanticipated component

$$
\Delta o_{t}^{U}=\Delta o_{t}-\left(\Delta o_{t}^{F}+\gamma_{o 2}\right)=\Delta \eta_{t}+\beta_{0}\left[\left(z_{t}-z_{t \mid t}\right)-\left(z_{t-1}-z_{t-1 \mid t-1}\right)\right]
$$

is the sum of the change in the stationary error $\eta_{t}$ and the change in the error from filtering the stochastic trend, $z_{t}-z_{t \mid t}$.

If we use $\Delta o_{t}^{F}+\gamma_{o 2}$, the change in the forecasted average of un-discounted oil prices, instead of $\Delta o_{t}^{F}$ in the GDP regression, the estimates of parameters $\left(\alpha_{k}\right),\left(\pi_{k}^{F}\right)$ and $\left(\pi_{k}^{U}\right)$ would not be altered, since $\gamma_{o 2}$ is absorbed in $\delta^{*}$.

\subsection{Identification of a Global Oil Market Fundamental}

We may interpret $\left(z_{t}\right)$ as a global oil market fundamental, because forecasted long-term average discounted oil prices are primarily driven by estimates of $\left(z_{t}\right)$. Note that $\left(z_{t}\right)$ reflects long-term fluctuations around a linear trend. We may interpret these fluctuations as longterm deviations from Hotelling's (1931) perfect competition model. Hotelling showed that under a monopoly pricing scheme, demand for oil also plays a part in determining its price. In this light, and since hydrocarbons are vital to the global economy, such fluctuations of the stochastic trend may reflect similar long-term fluctuations in global real economic activity. If so, then we may expect that the stochastic trend $\left(z_{t}\right)$ is common to both real oil prices and global real economic activity, if long-term supply is relatively steady. These series may have different linear trends but common long-term stochastic fluctuations around these linear trends.

Similarly to (3), we let

$$
w_{t}=\gamma_{w 1}+\gamma_{w 2} t+\beta_{w} z_{t}+\eta_{t}^{w}
$$


where $\left(w_{t}\right)$ is global real economic activity and $\left(z_{t}\right)$ is the same latent stochastic trend. ${ }^{9}$ With this representation, we specifically mean that three series are cointegrated: (i) fluctuations of $\left(o_{t}\right)$ around a linear trend, (ii) fluctuations of $\left(w_{t}\right)$ around a different linear trend, and (iii) the common stochastic trend $\left(z_{t}\right)$. The cointegrating vector - orthogonal to $\left(\beta_{o}, \beta_{w}\right)^{\prime}$ - does not cointegrate $\left(o_{t}\right)$ and $\left(w_{t}\right)$, because they may have different linear trends. Rather, it cointegrates their fluctuations around those linear trends.

The models in (3) and (5) may be estimated jointly using the Kalman filter. ${ }^{10}$ Using a similar model but without linear trends, Chang et al. (2009) showed that the steady-state Kalman filter with unit root in $\left(z_{t}\right)$ is an absolutely summable linear process. Summability implies that estimates of $\left(z_{t}\right)$ inherit their order of integration from $\left(o_{t}\right)$ and $\left(w_{t}\right)$. If these series are cointegrated, as our empirical evidence below suggests, the Kalman filter provides an estimate that is cointegrated with the true trend. On the other hand, if these series are $\mathrm{I}(0)$, then estimates of $\left(z_{t}\right)$ will also be $\mathrm{I}(0)$. Cointegration provides a convenient way to identify $\Delta o^{F}$ and is consistent with subsequent first-differencing. However, even if these very persistent series are $\mathrm{I}(0)$, the Kalman filter still identifies a persistent component $\Delta o^{F}$.

An alternative to the cointegration model of oil price and global real economic activity to estimate the stochastic trend is to apply the Kalman filter to the oil price model (3) only. Besides the theoretical argument that the long-term demand for oil is driven by global economic growth, we have empirical motivation for modeling the stochastic trend in oil prices jointly with global real economic activity. Joint estimation utilizes more information to identify the fundamental, which has smoother changes than the oil price changes themselves. This distinction is important over the duration of especially volatile periods. For example, the rapid oil price changes from the early 1970s to 1980 and from 2003 to 2007 make it difficult to forecast long term oil prices based only on historical oil prices. Historical data on the global economy may be particularly informative on the future longterm oil price during these periods. This intuitive argument is confirmed quantitatively in our comparison of competing models for forecasting accuracy of the long-term average price. The model proposed above dominates a battery of univariate state-space models and rule-of-thumb forecasting models.

The identification scheme using (3) and (5) may be augmented with more covariates and adding more equations. In that case, additional latent fundamentals may be added to reflect multiple stochastic trends.

\section{Data and Empirical Results}

A quarterly real oil price series is created for 1971-2008 by dividing the monthly West Texas Intermediate spot oil price by the monthly producer price index (all commodities) and taking a quarterly average of the resulting series. Global real economic activity is

\footnotetext{
${ }^{9}$ This assumption is supported by the panel data study of Lee (2005), which showed that oil consumption and GDP are cointegrated in many countries.

${ }^{10}$ See Harvey (1989), Hamilton (1994), or Kim and Nelson (1999) for detailed exposition on the Kalman filter.
} 
measured using global real GDP. ${ }^{11,12}$

\subsection{Augmented Oil Market Model}

\section{Insert Figure 1 About Here}

Figure 1 (top panel) shows linearly detrended log global real economic activity and linearly detrended log real oil prices scaled by $1 / 10$. Although these series appear to move together remarkably since the oil price collapse of 1986 and before the Iranian Revolution of 1979, cointegration cannot be decisively detected over the whole sample period. Since the magnitude of the 1979 increase and 1986 decrease appear to be roughly similar relative to the linear trend, we consider an indicator $\left(b_{t}\right)$ for 1979Q3-1985Q4. The purpose of the indicator is simply to control for the apparent mean shift in the data. The increase in 1979 has been conventionally attributed to the announcement of the removal of price controls in the U.S. in conjunction with supply disruptions in the oil market caused by the Iranian Revolution in 1979, followed by the Iran-Iraq War and OPEC production cuts. The notion that this increase was driven by supply has been supported recently by Kilian (2008), although Kilian (2009) and Kilian and Murphy (2010) also attributed some of this increase to precautionary demand.

In either case, Figure 1 (bottom panel) shows that the inclusion of the indicator in detrending brings the mean oil price during this period in line with what might be expected without the sharp increase. Inclusion shows clearer evidence of cointegration over the whole sample period, using a standard Phillips-Ouliaris (1990) residual-based test: the null of no cointegration is rejected at 5\% significance. A heuristic explanation is that the long-term global GDP is correlated with the long-term demand for oil and that this relationship is captured by the estimated cointegration. The cointegration is more prominently identified after controlling for the 1979Q3-1985Q4 period using the indicator.

We augment the oil market model given by (3) and (5) with

$$
\begin{aligned}
o_{t} & =\gamma_{o 1}+\gamma_{o 2} t+\gamma_{o 3} b_{t}+\beta_{o} z_{t}+\eta_{t}^{o} \quad \text { and } \\
w_{t} & =\gamma_{w 1}+\gamma_{w 2} t+\gamma_{w 3} b_{t}+\beta_{w} z_{t}+\eta_{t}^{w},
\end{aligned}
$$

using the indicator $\left(b_{t}\right)$. It is important to note the econometric effect of the indicator. If a mean shift occurred in 1979 with reversion to the previous mean in 1986, then the regressions in (6) and (7) are cointegrating. If instead the models in (3) and (5) are estimated, and the

\footnotetext{
${ }^{11}$ Annual global GDP data are obtained from Angus Maddison's historical statistics (Maddison, 2010, http://www.ggdc.net/Maddison) for 1971-2008. Quarterly OECD GDP is used to interpolate global GDP at a quarterly frequency. The interpolation is linear in the difference between the log of the two series, similarly to Friedman's (1962) imputation by related series. Due to the stochastic trend shared by an I(1) low-frequency series and its imputed high-frequency counterpart, imputation bias is asymptotically negligible and may be preferable to the inefficiency that would result from estimation at the lower frequency (Miller, 2010).

${ }^{12}$ We also tried the shipping index that Kilian (2009) used to proxy global real economic activity. Empirical evidence suggests that this index is not cointegrated with log real oil prices. Miller and Ratti (2009) found that oil prices are cointegrated with stock market prices in many OECD countries. However, they did not find the relationship to be stable.
} 
indicator is relegated to the error term, the regressions do not lose cointegration, because the indicator itself is not an explosive trend. However, including the indicator improves estimation. ${ }^{13}$ We present results with and without the indicator throughout the discussion of the oil market model in this section.

\section{Insert Table 1 About Here}

Empirical results from the oil market model given by (3) and (5) and by (6) and (7) are shown in Table 1. These results appear to be robust to inclusion or exclusion of the indicator.

The linear trend coefficient estimates of 0.0106 and 0.0086 for quarterly series suggest annualized average growth rates of $4.31 \%$ for real oil prices and $3.48 \%$ for global real economic activity. These rates are consistent with our expectations. Moreover, the fact that $\beta_{o}$ and $\beta_{w}$ have the same sign suggests positive cointegration of real oil prices and global real economic activity around their respective average growth rates. Naturally, as a factor of production, long-term fluctuations in oil prices should be much larger - by a factor of about 10 in the table and in Figure 1 - than long-term fluctuations in global economic activity.

\subsection{Long-Term Forecasting Comparison}

\section{Insert Table 2 About Here}

Table 2 compares $N$-period ahead forecasted averages using seven alternative oil price forecasting models with forecasts based on our global oil market model given jointly by (3) and (5) or by (6) and (7). Specifically, it shows the MSE of forecasts from our model and seven alternative models. The alternative models are a random walk, random walk with drift, three univariate state-space models with different signal-to-noise ratios, the oil equation complementing the GDP equation (1) from a bivariate VAR, and a naive moving $N$-period average. See Appendix A for a more detailed discussion of these models.

We conduct out-of-sample rolling forecasts but using whole-sample parameter estimates. Although not ideal in cases where a sufficiently large sample is available, we use the whole sample for parameter estimates for four reasons. First, the maximum forecast window of 40 quarters substantially reduces the sample, and breaking it into subsamples for estimation and out-of-sample forecasting would further reduce the sample size used for estimation. Second, the beginning of the sample (the 1970s and 1980s) is unusually problematic if we do not control for the 1979-85 period. As illustrated in Figure 1, much of the correlation between the two series becomes evident after 1986. Third, we would like to include 1979-85 in the forecasting model comparisons, since this was a controversial period in oil markets. And fourth, if we $d o$ control for the 1979-85 period, the point estimates for the whole sample or an early sub-sample are similar.

Of all models considered, the random walk models provide the best one-step ahead forecasts, since they yield the smallest MSEs at $N=1$. At $N=40$, our model outperforms all

\footnotetext{
${ }^{13}$ It is straightforward to show that if the mean shift occurred and $\left(z_{t}\right)$ were observed, least squares estimation of $\beta_{o}$ and $\beta_{w}$ in (6) and (7) would be $T$-consistent, while least squares estimation in (3) and (5) would be only $\sqrt{T}$-consistent with a more complicated limiting distribution.
} 
seven other models. This result holds regardless of the indicator specification. We interpret this to mean that the random walk models provide the best short-horizon forecasted averages, while our model provides the best long-horizon forecasted averages.

Between columns for $N=1$ and $N=40$, the table shows the threshold value beyond which our model dominates up to $N=40$. Average forecasts from our model dominate those from a random walk and random walk with drift at 10, 14, or 7 quarters or more, depending on the indicator specification. Note that the most conservative of the indicator approaches is to include the indicator in the model, but exclude it from the forecast. Under this approach, the random walk models hold out for 13 quarters against our model.

The forecasting performance of the univariate Kalman filter hinges on the signal-tonoise ratio. With relatively large noise, the univariate model almost never outperforms our model. With a very large signal, the univariate Kalman filter approximates the random walk model, unless the indicator is excluded from the forecast. An advantage of our model over the univariate specifications is that the covariate, global real economic activity, identifies an appropriate signal-to-noise ratio.

Forecasts using the oil equation of a bivariate oil price-macroeconomy VAR, cumulated to forecast levels, never dominate those from our model.

Finally, we consider a naive $N$-period moving average forecasting model that dampens the volatility of the random walk model. For $N=1$, this reduces to the random walk model. For $N=40$ this approach shows very weak forecasts.

Overall, our model performs best among those considered for forecasts of averages of 1 to $N$-periods ahead for $N \geq 26$ quarters. It performs second best for $14 \leq N<26$ quarters. Since the lifespan of energy-intensive goods typically exceeds 14 quarters, and the planning horizon of households is typically multiple years, our model provides an appropriate longhorizon forecasting specification.

\subsection{Decomposition}

In constructing the decomposition of $\left(\Delta o_{t}\right)$, we include the indicator to improve estimation of the oil market model. However, we take the more conservative approach of leaving the indicator in the unanticipated component $\left(\Delta o_{t}^{U}\right)$ rather than in the forecasted component. Empirically, including the indicator in $\left(\Delta o_{t}^{U}\right)$ makes little difference in comparing point estimates with a decomposition without the indicator, since the first difference of the indicator for 1979Q3-1985Q4 is only non-zero at two points, 1979Q3 and 1986Q1.

On the other hand, the results of Table 2 suggest that if an appropriate covariate can be found to proxy for the 1979-85 episode in place of the indicator, so that the mean shift is included in $\left(\Delta o_{t}^{F}\right)$, the forecasting ability of the oil market model might be improved.

Insert Figure 2 About Here

Figure 2 illustrates the estimated components $\left(\Delta o_{t}^{F}\right)$ and $\left(\Delta o_{t}^{U}\right)$ in comparison with $\left(\Delta o_{t}\right)$. Notice that the forecasted component is much smoother than the oil price itself. All of the major oil price spikes are unanticipated, except for some part of the recent downward spike, which also correlates with a downward spike in both global and US real GDP. 


\title{
3.4 Results from the US GDP Models
}

\author{
Insert Table 3 About Here
}

Table 3 displays coefficient estimates and t-test statistics from the models in (1) and (2), as well as a model using only $\Delta o^{F}$ to measure oil. In Table 3, these models are labeled respectively as Models 1,3 , and 2 .

As Pagan (1984) noted, standard error estimates may be incorrect when using forecasts from another model as regressors, which is the case in Models 2 and 3. That issue pertains to our two-step technique, but since the oil forecasting model has an unobserved regressor and the US GDP model is in first differences, Pagan's suggested correction would not be straightforward to adapt. Instead we take a nonparametric bootstrap approach, so that critical values are tailored to the unknown null distributions of the test statistics. Since these models are dynamic, we follow the suggested restricted sampling technique of van Gierbergen and Kiviet (2002). We conduct 10,000 bootstrap iterations for each coefficient in each of the models.

Note that replacing first-differenced regressors in Model 1 with $\Delta o^{F}$ in Model 2 increases the fit (in $R^{2}$ ) by $4 \%$. Moreover, the coefficients are substantially larger - these regressors have a smaller variance - and generally more significant. Adding $\Delta o^{U}$ (Model 3), does much less to improve the fit - an increase of $1.5 \%$, but with the four additional regressors.

\section{Insert Table 4 About Here}

Table 4 shows three additional models. Model 4 includes only oil price increases, denoted by $\Delta^{+} o$, in the spirit of Mork (1989), while Model 5 includes only net oil price increases (NOPI), in the spirit of Hamilton $(1996,2003)$. Compare these with Model 6, using only increases in unanticipated deviations from the forecasted average, denoted by $\Delta^{+} o^{U}$, which includes the major oil price spikes that Mork and Hamilton intended to capture with their measures. The signs and magnitudes of estimates using all three models are roughly similar. The fit of NOPI is the best among these three. In fact, $\Delta^{+} o^{U}$ does not show much improvement in fit over simple first differences. Out of all of the models using only one set of oil regressors (Models 1, 2, 4, 5, and 6), the models using NOPI and $\Delta o^{F}$ have the best - roughly comparable - fit.

\section{Insert Table 5 About Here}

Table 5 shows the final three models. These are essentially variations of the model given by (2), Model 3, but allowing for the possibility of asymmetric responses of GDP. $\left(\Delta^{+}\right.$and $\Delta^{-}$denote only positive and negative changes respectively.) Allowing asymmetric responses to $\Delta o^{F}$ increases fit by only $2 \%$ (Model 2 to Model 7 ). Considering $\Delta^{-} o^{U}$ as well as $\Delta^{+} O^{U}$ increases fit by just over $2 \%$ (Model 6 to Model 8 ). Model 9, the most inclusive, naturally has the highest fit, and also the highest penalized fit ( $\bar{R}^{2}$, not shown).

\subsection{Cumulative Conditional Responses}

In order to see more clearly the effects on real GDP implied by the coefficient estimates of Model 9, we construct cumulative conditional responses, similar to those estimated by Kilian 
(2009). ${ }^{14}$ As Kilian noted, the errors of the models used to estimate these responses are serially correlated. We circumvent the serial correlation by estimating the dynamic model, and then inverting it - similarly to inverting a VAR to get impulse response functions. In this way our estimation is both parsimonious and efficient. The reader is referred to Appendix B for more details.

\section{Insert Figure 3 About Here}

Figure 3 shows the cumulative conditional response of US real GDP to unit increases in $\Delta^{+} o_{t}^{F}, \Delta^{+} o_{t}^{U}$ or unit decreases in $\Delta^{-} o_{t}^{F}, \Delta^{-} o_{t}^{U}$, net of lagged real GDP and holding constant the other oil-related regressors and future stochastic changes in the same component. Although a unit increase in $\Delta^{+} o_{t}^{F}$ may be correlated with future changes $\Delta^{+} o_{t+j}^{F}$ and $\Delta y_{t+k}$, which also have impacts on $\Delta y_{t+q}$ for $j, k<q$, we isolate only the effects of $\Delta^{+} o_{t}^{F}$ directly on $\Delta y_{t+1}, \ldots, \Delta y_{t+q}$ and not indirectly through either $\Delta^{+} o_{t+j}^{F}, \Delta y_{t+k}$, or the other oil-related regressors. These direct effects are then cumulated. Specifically, we re-estimate Model 9 with oil-related regressors orthogonalized with respect to lagged real GDP. Because of the orthogonalization before inversion, the regressors and error are uncorrelated, so the response to a one unit change in one of the real oil component regressors may be interpreted as net of lagged real GDP, similarly to Kilian's (2009) static model.

The cumulative conditional response of an increase in $\Delta^{+} o_{t}^{F}$ appears to be quite large and the edge of the $90 \%$ confidence band falls close to zero. A one-time $1 \%$ increase in $\Delta^{+} o_{t}^{F}$, holding the other components constant, is correlated with a $0.11 \%$ decrease in real GDP growth, fully realized after about 4 quarters. In contrast, a one-time $1 \%$ increase in $\Delta^{+} o_{t}^{U}$ has a significant impact with a similar cumulative shape, but only about a $0.05 \%$ cumulative impact. The responses to $\Delta o^{F}$ appear to be symmetric in sign - that is, increases are followed by decreases in real GDP growth, and decreases are followed by increases in real GDP growth, while different in magnitude - the cumulative effect of a decrease in $\Delta^{-} o_{t}^{F}$ is only $0.07 \%$. On the contrary, responses to $\Delta o^{U}$ appear to be both asymmetric in sign - both increases and decreases are followed by decreases in real GDP growth, and in magnitude - the cumulative effect of a $1 \%$ decrease in $\Delta^{-} o_{t}^{U}$ is only about $0.025 \%$.

\subsection{Counterfactual GDP Growth}

The remaining figures, Figures 4 and 5, show the actual log difference of US real GDP (real GDP growth) compared with four different counterfactual paths for GDP real growth created by omitting various orthogonalized components of oil price changes. The methodology used is similar to that used for the conditional response analysis above, and is described in detail in Appendix B. The important point is that the regressors, after orthogonalization and inversion, are not correlated with the residual. As a result, a counterfactual without lagged real oil price growth - or without a component of real oil price growth - is created by subtracting out only the part uncorrelated with lagged GDP growth and uncorrelated with

\footnotetext{
${ }^{14}$ These responses are to the orthogonalized regressors rather than to structural shocks in a restricted VAR. Consequently, our empirical finding of asymmetry contrasts with the rejection of asymmetric responses to structural shocks by Kilian and Vigfusson (2009).
} 
the other components of real oil price growth. That way, lagged real GDP growth itself is not omitted as an explanatory variable of current real GDP growth in the counterfactual. Otherwise, if some part of lagged real GDP growth were omitted, the importance of oil would be overstated.

The intercept still reflects deterministic changes in oil price growth. The counterfactuals may therefore be interpreted as what real GDP growth would have been if real oil prices had followed the estimated linear trend without fluctuations.

\section{Insert Figure 4 About Here}

The top panel of Figure 4 shows a counterfactual constructed by omitting the lagged real oil price growth terms from Model 1 as a baseline. Over most of the sample, the counterfactual without real oil price fluctuations estimated using this model appears roughly similar to actual real GDP growth. These results suggests that without real oil price fluctuations, the 1974 recession would have been eliminated, while those of 1980 and 1991 would have been just barely mitigated. Because the sum of the coefficients of the lags of the oil price is negative, Model 1 predicts a large boom following the 1986 oil price collapse and a significant slowdown without the oil price collapse. The absence of the predicted boom by the benchmark model is an important empirical motivation for allowing asymmetric responses of real GDP to real oil price increases and decreases. The counterfactual from this model has little to say about the effect on real GDP growth of the oil price run-up of the 2000s.

The bottom panel of Figure 4 shows a similar counterfactual, but based on subtracting out all of the oil terms of Model 9, rather than Model 1. The recession of 1974 is actually reversed. The recessions of 1980 and 1991 are also mitigated, but not eliminated. However, the recovery from each recession is stronger under the counterfactual.

The 1986 oil price collapse seems to have had two effects. Without it, under the counterfactual, there would have been a short stagnation, but a large subsequent increase. The main effect of the oil price collapse seems to have been deleterious rather than salutary. As Elder and Serletis (2010) showed, the collapse coincides with a surge in conditional volatility in oil prices. The negative effect we found is not net of the uncertainty. In fact, it is reasonable to speculate that the negative effect of temporary declines in oil prices stems mainly from increased uncertainty and that the uncertainty is the cause of the negative effect on GDP. If we were to include a proxy for uncertainty in the GDP equation, then we would expect the coefficients of $\Delta^{-} o^{U}$ to turn positive. Edelstein and Kilian (2007) took a different view. They attributed the lack of a boom to other factors, such as the Tax Reform Act of 1986.

A more dramatic cumulative effect of oil in the 2000s is evident from the sustained gap between the actual and counterfactual real GDP growth rates. During 2003-07, the annualize quarterly real GDP growth rate was $2.91 \%$. The counterfactual using Model 1 suggests that the run-up in real oil prices in excess of the linear trend decreased the annual growth rate by $0.58 \%$, while that using Model 9 suggests the impact of this run-up was an annual growth rate decrease of $1.35 \%$.

Insert Figure 5 About Here 
Finally, Figure 5 shows counterfactuals without $\Delta^{+} o^{F}$ and $\Delta^{-} o^{F}$ (top panel) and without $\Delta^{+} o^{U}$ and $\Delta^{-} o^{U}$ (bottom panel) from Model 9. In addition to orthogonalizing these with respect to real GDP, they are also orthogonalized with respect to each other. That is, we shut down only the parts of $\Delta^{+} o^{F}$ and $\Delta^{-} o^{F}$ orthogonal to $\Delta^{+} o^{U}$ and $\Delta^{-} o^{U}$, and vice versa.

$\Delta^{+} o^{U}$ and $\Delta^{-} o^{U}$ appear to play a more important role during episodes of 1974, 1986, and 1991, but are relatively unimportant during 2003-07. In contrast, $\Delta^{+}{ }_{O^{F}}$ and $\Delta^{-}{ }^{-}{ }^{F}$ appear to be less important during the former episodes, but more important during 200307.

\section{Concluding Remarks}

Empirical studies on oil prices and the macroeconomy have generally focused on the effect of shocks to (nonlinear functions of) oil prices. In this study, we decompose real oil price changes into changes in forecasted long-term average real oil prices, $\Delta o^{F}$, and changes in unanticipated deviations of actual current prices from these forecasted averages, $\Delta o^{U}$.

The second component is highly correlated with real oil price changes. Its asymmetric relationship with future real GDP growth is qualitatively similar to that reported in previous studies, such as Mork's (1989). Since we postulate oil as a factor of production in global real economic activity, some likely sources for these short-term fluctuations around the estimated long-term fundamental include phenomena otherwise unexplained by our model, such as temporary supply disruptions, precautionary demand (along the lines of Kilian, 2009), and speculation by investors.

Major innovations in oil prices, which are dominated by this second, unanticipated component, create uncertainty. We speculate that this uncertainty is an important channel through which large but temporary oil price changes affect the macroeconomy. A dramatic price change may result in heightened uncertainty regarding future real oil prices. In that case, there is an option value of waiting. Facing heightened uncertainty created by large positive or negative changes in price, the economic agent may put off decisions to purchase energy-intensive or energy-efficient cars or to install oil-burning or coal-burning electricity generators, for example. The oil price increases of the 1970s, in particular, may have created enough uncertainty to negatively affect real GDP, as suggested by Hamilton (1983). The large decrease of 1986 may have created enough uncertainty to negatively - rather than positively - affect GDP. ${ }^{15}$ The uncertainty channel implies asymmetry in the response of GDP growth, as estimates in Table 5 and Figure 3 show.

In contrast, changes in the forecasted long-term average of real oil prices relate to future real GDP growth in a different fashion. A decline in the forecasted average has a positive effect on the investment and consumption decision, while an increase in the forecasted average has a negative effect. This view is consistent with the notion that these changes affect demand through an income effect or through changes in user costs of energy-intensive

\footnotetext{
${ }^{15}$ This is because the sum of the coefficients on unanticipated oil price decreases in the GDP equation is positive in Model 9 (0.021). Using a different data sample (1949Q1-1988Q2), Mork (1989) found that the sum of the coefficients on four lags of oil price decreases is a moderately positive 0.017 .
} 
goods. ${ }^{16}$

Changes in the forecasted long-term average oil price are much smoother but have a significant impact on future real GDP growth. We argue that the impact of oil price changes is understated if one focuses only on unanticipated oil price shocks and does not take into account long-term forecasts. As Figure 4 shows, a regression with real oil price changes suggests little impact of the persistent run-up in oil prices from 2003-07 on GDP. Using decomposed series, we conclude that the persistent run-up in oil price from 2003-07 reduced US GDP by about $1.35 \%$ annually during that period. The impact is substantial despite the absence of a severe recession. Had the run-up not occurred, real GDP annual growth would have been about $4.26 \%$ instead of $2.91 \%$.

This point estimate appears to be too large in light of the oil share of GDP. However, an increase of $\$ 30$ per barrel in the forecast of the long-term average price with a $4 \%$ annual discount rate (our estimate of $\gamma_{02}$ ) and $\$ 10$ million net imports per day (by EIA estimates for the US) is equivalent to about $\$ 2.7$ trillion in present value, or about $20 \%$ of US GDP. A negative income effect alone of that magnitude can materially slow down growth in consumption and investment. Figure 1 suggests that the 2003-07 run-up in oil prices is mostly due to the increase in world real economic activity (demand for oil), resulting in substantial increases in the forecasts of long-term average real prices. Despite the absence of a recession, by our estimate using Model 9 the cumulative impact of the run-up on real GDP ( $-6.78 \%$ over 20 quarters) is comparable to that of the oil crisis of 1974 ( $-5.98 \%$ over 5 quarters), mainly because the 2003-07 run-up is more persistent. Edelstein and Kilian (2009) suggested that the changing automobile industry played a part in differentiating the 2000s from the 1970s. Blanchard and Galí (2010) suggested that labor markets, monetary policy, and oil's share of GDP also played a part. Our finding does not contradict these explanations, nor does it contradict the fourth explanation of Blanchard and Galí (2010), "lack of concurrent adverse shocks." There were concurrent revisions of real oil price forecasts, but these were not unanticipated shocks.

The recognition of the negative impact of changes in the forecasted long-term average of oil prices has policy implications. If the main impact of the oil market on the macroeconomy is through the uncertainty created by large oil price shocks, then price stabilization - through active management of strategic reserves, e.g. - should be an important policy objective. On the other hand, if the forecast of the long-term average price is the key variable that influences the decision-making of households and firms, then pursuing energy policies that bring down long-term prices relative to an upward trend can stimulate more growth.

The main point that we wish to convey is that there exist multiple channels through which oil price movements may affect real economic growth, and that the reaction of GDP growth to oil price changes differs across these channels. We argue that the most meaningful

\footnotetext{
${ }^{16}$ There are economic reasons that responses to $\Delta o^{F}$ may also be asymmetric. Lee and Ni (2002) found differential effects of oil price shocks at the industry level. Sectoral imbalances caused by demand or supply movements in different sectors make it desirable to shift capital or labor from one sector to another. The resource and time costs associated with the sectoral shifts can generate an asymmetric GDP response to positive and negative changes in oil price forecasts. The magnitude of the asymmetry depends on the strength of the sectoral shift effect. Our empirical finding is that this is not the main channel of the oil price effect - at least not within four quarters, which is the lag length in our GDP regression.
} 
way to distinguish these channels is by filtering the long-term information conveyed by real price changes, in order to approximate economic agents' interpretations of these changes.

\section{Appendix A: Alternative Forecasting Models}

We denote by $v_{N, 0}$ the MSE from forecasts of an $N$-period average around the $N$-period average of actual values using the multivariate state-space model of the global oil market model given jointly by (3) and (5) or by (6) and (7).

We denote by $v_{N, 1}$ and $v_{N, 2}$ the same MSEs using forecasts from random walk and random walk with drift models

$$
o_{t}=o_{t-1}+u_{t} \quad \text { and } \quad o_{t}=o_{t-1}+\gamma_{o 2}+u_{t}
$$

respectively. (These are related to (3) by letting $\beta_{o} \Delta z_{t}=u_{t}$ and $\eta_{t}^{o}=0$, subtracting $o_{t-1}$ from both sides, cumulating both sides, and adding $\gamma_{o 1}=o_{1}$ to both sides.) In this sense, the random walk models may be represented as

$$
o_{t}=\gamma_{o 1}+\gamma_{o 2} t+\beta_{o} z_{t}
$$

with $z_{0}=0$, univariate state-space models with all signal and no noise.

We denote by $v_{N, 3}, v_{N, 4}$, and $v_{N, 5}$ the same MSEs using forecasts from a more general univariate state-space model given by (3) with signal-to-noise ratio set to $3 \beta_{o}^{2} T / 2,2 \beta_{o}^{2} T$, and $100 \beta_{o}^{2} T$ respectively (where $T$ is the sample size and $\beta_{o}$ is estimated). Specifically, the variance of $\Delta z_{t}$ is set to unity, so that the signal variance is $\beta_{o}^{2} T$. The variance of $\left(\eta_{t}^{o}\right)$ is set to $2 / 3,1 / 2$, and $1 / 100$ to get the desired ratios. Note that for a large signal-to-noise ratio, such as $100 \beta_{o}^{2} T$, the models in (3) and (8) are virtually the same, unless an indicator is included, as in (6).

We denote by $v_{N, 6}$ the same MSE using forecasts from the oil equation of a bivariate VAR of the growth rates of real oil prices and US GDP, cumulated to forecast the level, rather than difference of the log real oil price. That is, we estimate

$$
\Delta o_{t}=\delta_{o}+\sum_{k=1}^{p} \alpha_{k}^{o} \Delta y_{t-k}+\sum_{k=1}^{p} \pi_{k}^{o} \Delta o_{t-k}+\varepsilon_{t}^{o}
$$

which together with (1) forms a bivariate VAR. The forecasts are created by cumulating predictions $\widehat{\Delta o_{t}}$ from this model, and then adding the initial observation, so that $\widehat{o_{t}}=$ $\sum_{i=2}^{t} \widehat{\Delta o_{i}}+o_{1}$.

Finally, we denote by $v_{N, 7}$ the same MSE using an $N$-period naive moving average to smooth the forecasts, so that $\widehat{o_{t}}=\frac{1}{N} \sum_{j=0}^{N-1} o_{t-j}$.

\section{Appendix B: Response and Counterfactual Methodologies}

Consider the benchmark model given by (1), and define $\zeta_{t-1}=\left(\Delta y_{t-1}, \ldots, \Delta y_{t-p}\right)^{\prime}, \vartheta_{t-1}=$ $\left(\Delta o_{t-1}, \ldots, \Delta o_{t-p}\right)^{\prime}, \pi=\left(\pi_{1}, \ldots, \pi_{p}\right)^{\prime}$, and $\alpha=\left(\alpha_{1}, \ldots, \alpha_{p}\right)^{\prime}$. Define

$$
\hat{\Xi}_{T} \zeta_{t-1}=\sum_{t} \vartheta_{t-1} \zeta_{t-1}^{\prime}\left(\sum_{t} \zeta_{t-1} \zeta_{t-1}^{\prime}\right)^{-1} \zeta_{t-1}
$$


to be an orthogonal projection of $\left(\vartheta_{t-1}\right)$ onto the space spanned by $\left(\zeta_{t-1}\right)$. We may rewrite the model as

$$
\Delta y_{t}=\delta+\left(\alpha^{\prime}+\pi^{\prime} \hat{\Xi}_{T}\right) \zeta_{t-1}+\pi^{\prime}\left(\vartheta_{t-1}-\hat{\Xi}_{T} \zeta_{t-1}\right)+\varepsilon_{t},
$$

where $\left(\vartheta_{t-1}-\hat{\Xi}_{T} \zeta_{t-1}\right)$ is the component of $\vartheta_{t-1}$ that is orthogonal to $\zeta_{t-1}$, and $\left(\alpha^{\prime}+\pi^{\prime} \hat{\Xi}_{T}\right) \zeta_{t-1}$ captures the contribution to $\left(\Delta y_{t}\right)$ of both lagged $\left(\Delta y_{t}\right)$ 's and any part of lagged $\left(\Delta o_{t}\right)$ 's correlated with the lagged $\left(\Delta y_{t}\right)$ 's. It is essential to purge this correlation, which exists by assumption of the model, in order to isolate the effect of lagged $\left(\Delta o_{t}\right)$ 's directly on $\left(\Delta y_{t}\right)$ and not indirectly through lagged $\left(\Delta y_{t}\right)$ 's.

Next, define $\Xi=\mathbf{E} \vartheta_{t-1} \zeta_{t-1}^{\prime}\left(\mathbf{E} \zeta_{t-1} \zeta_{t-1}^{\prime}\right)^{-1}$ and note that $\hat{\Xi}_{T}-\Xi=o_{p}(1)$ due to stationarity of $\left(\Delta o_{t}\right)$ and $\left(\Delta y_{t}\right)$. Define $\alpha(z)=1-\sum_{k=1}^{p}\left(\alpha_{k}+\pi_{k}^{*}\right) z^{k}$ where $\pi_{k}^{*}$ is the $k^{\text {th }}$ column of the row vector $\pi^{\prime} \Xi$ and $\pi(z)=\sum_{k=0}^{p-1} \pi_{k+1} z^{k}$, so that the model may be rewritten as

$$
\alpha(L) \Delta y_{t}=\delta+\pi(L)\left(\Delta o_{t-1}-\hat{\Xi}_{T} \zeta_{t-1}\right)+\pi^{\prime}\left(\hat{\Xi}_{T}-\Xi\right) \zeta_{t-1}+\varepsilon_{t},
$$

where $L$ is the lag operator. Note that $L^{k} \hat{\Xi}_{T} \zeta_{t-1}=\sum_{t} \vartheta_{t-1-k} \zeta_{t-1}^{\prime}\left(\sum_{t} \zeta_{t-1} \zeta_{t-1}^{\prime}\right)^{-1} \zeta_{t-1}$ is an orthogonal projection of $\left(\vartheta_{t-1-k}\right)$ onto the space spanned by $\left(\zeta_{t-1}\right)$.

Now, inverting the polynomial $\alpha(z)$, which is invertible by stationarity of $\left(\Delta y_{t}\right)$, we get

$$
\Delta y_{t}=\frac{\delta}{\alpha(1)}+\varphi(L)\left(\Delta o_{t}-L^{-1} \hat{\Xi}_{T} \zeta_{t-1}\right)+\psi(L) \pi^{\prime}\left(\hat{\Xi}_{T}-\Xi\right) \zeta_{t-1}+\psi(L) \varepsilon_{t},
$$

where $\sum_{k=0}^{\infty} \varphi_{k} z^{k}=\varphi(z)=\alpha(z)^{-1} \pi(z), \psi(z)=\alpha(z)^{-1}$, and $\varphi_{0}=0$. The cumulative effect on $\left(\Delta y_{t}\right)$ of a unit increase in $\Delta o_{t-q}$ for some $q>0$ holding lagged $\left(\Delta y_{t}\right)$ constant is given by $\sum_{k=0}^{q} \varphi_{k}$. The coefficients $\left(\varphi_{k}\right)$ may be identified using a standard autoregressive inversion formula with least squares estimates of $\left(\alpha_{k}\right)$ and $\left(\pi_{k}\right)$. The same projection and inversion may be performed on any of the models with decomposed oil price series, simply by substituting the decomposition for $\left(\Delta o_{t}\right)$. The coefficients on each decomposed series must be identified separately and interpreted as holding constant lagged $\left(\Delta y_{t}\right)$ and the other oil price components.

We use $\sum_{k=0}^{q} \varphi_{k}$ to compute the cumulative conditional response functions, or similar coefficients from the decomposed series, with confidence intervals created from 10,000 bootstrap iterations using residuals estimated from the original model. The bootstrap data generating process is similar to (10) with the order $q$ of $\varphi(L)$ set to 12 . The differences are the additional oil components in Model 9 and that the bootstrapped models are generated without orthogonalization. (Orthogonalization is primarily for identification and is not necessary in the data generating process.) The reason for using an inverted model a static model with parametric serial correlation, rather than Model 9 - a dynamic model - is to avoid potential pitfalls similar to that noted by van Gierbergen and Kiviet (2002) using interval-based bootstrap tests with dynamic models.

To compute the counterfactual GDP growth series, we "shut down" the effect of oil prices net of lagged GDP by subtracting $\varphi(L)\left(\Delta o_{t}-L^{-1} \hat{\Xi}_{T} \zeta_{t-1}\right)$ from $\Delta y_{t}$. Once the coefficients $\left(\varphi_{k}\right)$ are identified, this may be accomplished by regressing each $\left(\Delta o_{t-k}\right)$ up to $q$ onto $\left(\zeta_{t-1}\right)$ to create $\varphi(L) L^{-1} \hat{\Xi}_{T} \zeta_{t-1}$. Specifically, we regress out $p$ lags of GDP growth from $p$ lags oil price growth to get the third term on the right-hand-side of (9), then we 
estimate the dynamic model in (9) to get $\alpha(z)$. We then invert $\alpha(z)$ to get $q$ terms of $\varphi(z)$ in the static model in (10). Finally, we regress out $p$ lags of GDP growth from $q$ lags of oil prices growth to get the second term of (10), which we subtract from $\left(\Delta y_{t}\right)$ to get the counterfactuals for Model 1. Generalizing to Model 9, we have more oil-related regressors. In order to compute the counterfactuals without subcomponents of $\left(\Delta o_{t}\right)$, we simply regress out the subcomponents as well as GDP growth in the last step, immediately before subtracting from $\left(\Delta y_{t}\right)$. 


\section{References}

Balke, N.S., S.P.A. Brown, and M. Yücel (2002). "Oil Price Shocks and the U.S. Economy: Where Does the Asymmetry Originate?" The Energy Journal 233, 27-52.

Barsky, R.B. and L. Kilian (2002), "Do We Really Know that Oil Caused the Great Stagflation? A Monetary Alternative." In B.S. Bernanke and K. Rogoff (eds.), NBER Macroeconomics Annual 2001, pp. 137-183. Cambridge, MA: MIT Press.

Barsky, R.B. and L. Kilian (2004). "Oil and the Macroeconomy Since the 1970's," Journal of Economic Perspectives 18, 115-134.

Baumeister, C. and G. Peersman (2008). "Time-Varying Effects of Oil Supply Shocks on the U.S. Economy," Ghent University Faculty of Economics and Business Administration Working Paper.

Bernanke, B.S., M. Gertler, and M. Watson (1997). "Systematic Monetary Policy and the Effects of Oil Price Shocks," Brookings Papers on Economic Activity 1, 91-142.

Blanchard, O.J. and J. Galí (2010). "The Macroeconomic Effects of Oil Price Shocks: Why Are 2000's So Different from the 1970's?" In J. Galí and M. Gertler (eds.), International Dimensions of Monetary Policy, pp. 373-421. Chicago: University of Chicago Press.

Burbidge, J. and A. Harrison (1984). "Testing for the Effects of Oil-Price Rises Using Vector Autoregressions," International Economic Review 25, 459-484.

Chang, Y., J.I. Miller, and J.Y. Park (2009). "Extracting a Common Stochastic Trend: Theory with Some Applications," Journal of Econometrics 150, 231-247.

Edelstein, P. and L. Kilian (2007). "The Response of Business Fixed Investment to Changes in Energy Prices: A Test of Some Hypotheses about the Transmission of Energy Price Shocks," The B.E. Journal of Macroeconomics 7, Article 35.

Edelstein, P. and L. Kilian (2009). "How Sensitive Are Consumer Expenditures to Retail Energy Prices?" Journal of Monetary Economics 56, 766-779.

Elder, J. and A. Serletis (2010). "Oil Price Uncertainty," Journal of Money, Credit, and Banking 42, 1137-1159.

Friedman, M. (1962). "The Interpolation of Time Series by Related Series," Journal of the American Statistical Association 57, 729-757.

van Gierbergen, N.P.A. and J.F. Kiviet (2002). "How to Implement the Bootstrap in Static or Stable Dynamic Regression Models: Test Statistic Versus Confidence Region Approach," Journal of Econometrics 108, 133-156.

Gisser, M., and T.H. Goodwin (1986). "Crude Oil and the Macroeconomy: Tests of Some Popular Notions," Journal of Money, Credit, and Banking 18, 95-103. 
Hamilton, J.D. (1983). "Oil and the Macroeconomy since World War II," The Journal of Political Economy 91, 228-248.

Hamilton, J.D. (1994). Time Series Analysis. Princeton, NJ: Princeton University Press.

Hamilton, J.D. (1996). "This is What Happened to the Oil Price-Macroeconomy Relationship," Journal of Monetary Economics 38, 215-220.

Hamilton, J.D. (2003). "What is an Oil Shock?" Journal of Econometrics 113, 363-398.

Hamilton, J.D. (2009). "Understanding Crude Oil Prices," The Energy Journal 30, 179206.

Hamilton, J.D. and A.M. Herrera (2004). "Oil Shocks and Aggregate Macroeconomic Behavior: The Role of Monetary Policy," Journal of Money, Credit, and Banking 36, 265-286.

Harvey, A.C. (1989). Forecasting Structural Time Series Models and the Kalman Filter. Cambridge, UK: Cambridge University Press.

Herrera, A.M. and E. Pesavento (2009). "Oil Price Shocks, Systematic Monetary Policy, and the 'Great Moderation'," Macroeconomic Dynamics 13, 107-137.

Hooker, M.A. (1996). "What Happened to the Oil Price-Macroeconomy Relationship?" Journal of Monetary Economics 38, 195-213.

Hotelling, H. (1931). "The Economics of Natural Resources," The Journal of Political Economy 39, 137-175.

Jiménez-Rodríguez, R. (2009). "Oil Price Shocks and Real GDP Growth: Testing for Non-Linearity," The Energy Journal 30, 1-23.

Kilian, L. (2008). "Exogenous Oil Supply Shocks: How Big Are They and How Much Do They Matter for the U.S. Economy?" The Review of Economics and Statistics 90, 216-240.

Kilian, L. (2009). "Not All Oil Price Shocks Are Alike: Disentangling Demand and Supply Shocks in the Crude Oil Market," American Economic Review 99, 1053-1069.

Kilian, L. and D. Murphy (2010). "The Role of Inventories and Speculative Trading in the Global Market for Crude Oil," CEPR Discussion Paper 7753.

Kilian, L. and C. Park (2009). "The Impact of Oil Price Shocks on the U.S. Stock Market," International Economic Review 50, 1267-1287.

Kilian, L. and R.J. Vigfusson (2009). "Are the Responses of the U.S. Economy Asymmetric in Energy Price Increases and Decreases?" Manuscript, University of Michigan.

Kim, C.-J. and C.R. Nelson (1999). State-Space Models with Regime Switching. Cambridge, MA: MIT Press. 
Lee, C.-C. (2005). "Energy Consumption and GDP in Developing Countries: A Cointegrated Panel Analysis," Energy Economics 27, 415-427.

Lee, K., and S. Ni (2002). "On the Dynamic Effects of Oil Price Shocks: A Study Using Industry Level Data," Journal of Monetary Economics 49, 823-852.

Lee, K., S. Ni, and R.A. Ratti (1995). "Oil Shocks and the Macroeconomy: The Role of Price Variability," The Energy Journal 16, 39-56.

Maddison, A. (2010). "Statistics on World Population, GDP and Per Capita GDP, 1-2008 AD," Groningen Growth and Development Centre, Groningen University.

Miller, J.I. (2010). "Cointegrating Regressions with Messy Data and an Application to Mixed-frequency Series," Journal of Time Series Analysis 31, 255-277.

Miller, J.I. and R.A. Ratti (2009). "Crude Oil and Stock Markets: Stability, Instability, and Bubbles," Energy Economics 31, 559-568.

Mork, K.A. (1989). "Oil and the Macroeconomy When Prices Go Up and Down: An Extension of Hamilton's Results," The Journal of Political Economy 97, 740-744.

Mork, K.A., O. Olsen, and H.T. Mysen (1994). "Macroeconomic Responses to Oil Price Increases and Decreases in Seven OECD Countries," The Energy Journal 15, 19-35.

Pagan, A. (1984). "Econometric Issues in the Analysis of Regressions with Generated Regressors," International Economic Review 25, 221-247.

Phillips, P.C.B. and S. Ouliaris (1990). "Asymptotic Properties of Residual-Based Tests for Cointegration," Econometrica 58, 165-93.

Pindyck, R.S. (1999). "The Long-Run Evolution of Energy Prices," The Energy Journal $20,1-27$. 


\section{Tables and Figures}

\begin{tabular}{|c|c|c|}
\hline \multicolumn{3}{|c|}{ Table 1. Oil Forecasting Model Estimates } \\
\hline \hline & w/o Indicator & w/Indicator \\
\hline$\gamma_{o 1}$ & $0.2109(2.683)^{* * *}$ & $-0.0180(-0.289)$ \\
$\gamma_{o 2}$ & $0.0093(2.208)^{* *}$ & $0.0106(2.746)^{* * *}$ \\
$\gamma_{o 3}$ & & $0.6788(12.097)^{* * *}$ \\
$\beta_{o}$ & $0.0506(8.874)^{* * *}$ & $0.0470(11.424)^{* * *}$ \\
\hline$\gamma_{w 1}$ & $-0.0086(-1.798)^{*}$ & $-0.0086(-1.800)^{*}$ \\
$\gamma_{w 2}$ & $0.0086(22.174)^{* * *}$ & $0.0086(22.174)^{* * *}$ \\
$\gamma_{w 3}$ & & $-0.0004(-0.122)$ \\
$\beta_{w}$ & $0.0048(17.435)^{* * *}$ & $0.0048(17.434)^{* * *}$ \\
\hline
\end{tabular}

Table 1: Parameter estimates of the global oil market models given by (3) and (5) - without the 1979Q3-1985Q4 indicator - and by (6) and (7) - with the indicator - using the Kalman filter with steady-state conditional variances. T-statistics shown in parentheses. Significance at $10 \%, 5 \%$, and $1 \%$ denoted respectively by one, two, and three asterisks.

\begin{tabular}{|c|ccc|ccc|ccc|}
\hline \multicolumn{7}{|c|}{ Table 2. Oil Forecasting Model Comparisons } \\
\hline \hline & \multicolumn{3}{|c|}{ w/o Indicator } & \multicolumn{3}{c|}{ Indic. Not in KF Fore. } & \multicolumn{3}{c|}{ Indic. in KF Fore. } \\
& $v_{1}$ & $v_{N, i} \geq v_{N, 0}$ & $v_{40}$ & $v_{1}$ & $v_{N, i} \geq v_{N, 0}$ & $v_{40}$ & $v_{1}$ & $v_{N, i} \geq v_{N, 0}$ & $v_{40}$ \\
\hline$v_{N, 0}$ & 0.094 & & 0.074 & 0.113 & & 0.076 & 0.042 & & 0.188 \\
$v_{N, 1}$ & 0.018 & $N \geq 10$ & 0.200 & 0.018 & $N \geq 14$ & 0.200 & 0.018 & $N \geq 7$ & 0.200 \\
$v_{N, 2}$ & 0.018 & $N \geq 10$ & 0.192 & 0.018 & $N \geq 14$ & 0.192 & 0.018 & $N \geq 7$ & 0.192 \\
$v_{N, 3}$ & 0.082 & $N \geq 3$ & 0.230 & 0.120 & $N \geq 1$ & 0.108 & 0.082 & $N \geq 1$ & 0.243 \\
$v_{N, 4}$ & 0.072 & $N \geq 4$ & 0.233 & 0.098 & $N \geq 5$ & 0.110 & 0.068 & $N \geq 1$ & 0.251 \\
$v_{N, 5}$ & 0.022 & $N \geq 10$ & 0.202 & 0.058 & $N \geq 26$ & 0.101 & 0.021 & $N \geq 8$ & 0.205 \\
$v_{N, 6}$ & 0.253 & $N \geq 1$ & 0.374 & 0.253 & $N \geq 1$ & 0.374 & 0.253 & $N \geq 1$ & 0.374 \\
$v_{N, 7}$ & 0.018 & $N \geq 7$ & 0.282 & 0.018 & $N \geq 9$ & 0.282 & 0.018 & $N \geq 4$ & 0.282 \\
\hline
\end{tabular}

Table 2: MSE of predicted averages from forecasting models. Columns labeled with $v_{N, i} \geq v_{N, 0}$ show the threshold value at which (up to $N=40$ ) the multivariate state-space model of the global oil market model given jointly by (3) and (5) or by (6) and (7) is preferred for forecasted averages. Multivariate and univariate state-space models are estimated with and without the 1979Q3-1985Q4 indicator. See Appendix A for a detailed discussion of the alternative forecasting models considered. 
Table 3. US GDP Growth Equation Estimates

\begin{tabular}{|c|c|c|c|}
\hline \hline & Model 1 & Model 2 & Model 3 \\
\hline \hline$\Delta y_{t-1}$ & $0.259(3.032)^{* * *}$ & $0.242(2.084)^{* *}$ & $0.213(1.782)^{*}$ \\
$\Delta y_{t-2}$ & $0.106(1.193)$ & $0.288(2.439)^{* * *}$ & $0.259(2.141)^{* *}$ \\
$\Delta y_{t-3}$ & $0.000(0.003)$ & $0.158(1.350)$ & $0.133(1.110)$ \\
$\Delta y_{t-4}$ & $-0.019(-0.228)$ & $0.011(0.097)$ & $-0.002(-0.019)$ \\
$\Delta o_{t-1}$ & $-0.008(-1.528)$ & & \\
$\Delta o_{t-2}$ & $-0.006(-1.047)$ & & \\
$\Delta o_{t-3}$ & $-0.004(-0.670)$ & & \\
$\Delta o_{t-4}$ & $-0.009(-1.768)^{*}$ & & $-0.004(-0.159)$ \\
$\Delta o_{t-1}^{F}$ & & $-0.003(-0.122)$ & $-0.048(-2.025)^{* *}$ \\
$\Delta o_{t-2}^{F}$ & & $-0.050(-2.340)^{* *}$ & $-032(-1.335)$ \\
$\Delta o_{t-3}^{F}$ & & $-0.034(-1.545)^{*}$ & $-0.001(0.044)$ \\
$\Delta o_{t-4}^{F}$ & & $0.006(0.292)$ & $-0.004(-0.811)$ \\
$\Delta o_{t-1}^{U}$ & & & $-0.004(-0.694)$ \\
$\Delta o_{t-2}^{U}$ & & & $-0.002(-0.402)$ \\
$\Delta o_{t-3}^{U}$ & & & $0.006(-1.081)$ \\
$\Delta o_{t-4}^{U}$ & & & 0.230 \\
\hline$R^{2}$ & 0.174 & 0.215 & -1201 \\
\hline
\end{tabular}

Table 3: Parameter estimates from models given by (1) - Model 1 - and (2) - Model 3, and from a model with only $\Delta o^{F}$ - Model 2. Intercept estimates not shown. T-statistics shown in parentheses. Significance at $10 \%, 5 \%$, and $1 \%$ denoted respectively by one, two, and three asterisks, calculated using critical values from 10,000 bootstrap iterations. 
Table 4. US GDP Growth Equation Estimates

\begin{tabular}{|c|c|c|c|}
\hline \hline & Model 4 & Model 5 & Model 6 \\
\hline \hline$\Delta y_{t-1}$ & $0.223(2.594)^{* * *}$ & $0.205(2.380)^{* *}$ & $0.243(2.745)^{* * *}$ \\
$\Delta y_{t-2}$ & $0.062(0.705)$ & $0.049(0.560)$ & $0.065(0.710)$ \\
$\Delta y_{t-3}$ & $-0.008(-0.093)$ & $-0.015(-0.168)$ & $-0.019(-0.210)$ \\
$\Delta y_{t-4}$ & $-0.041(-0.483)$ & $-0.057(-0.671)$ & $-0.076(-0.861)$ \\
$\Delta^{+} o_{t-1}$ & $-0.009(-1.256)$ & & \\
$\Delta^{+} o_{t-2}$ & $-0.014(-1.966)^{*}$ & & \\
$\Delta^{+} o_{t-3}$ & $-0.008(-1.083)$ & & \\
$\Delta^{+} o_{t-4}$ & $-0.017(-2.239)^{* *}$ & & \\
$N O P I_{t-1}$ & & $-0.011(-1.237)$ & \\
$N O P I_{t-2}$ & & $-0.020(-2.305)^{* *}$ & \\
$N O P I_{t-3}$ & & $-0.014(-1.587)$ & $-0.008(-1.156)$ \\
$N O P I_{t-4}$ & & $-0.022(-2.560)^{* *}$ & $-0.011(-1.488)$ \\
$\Delta^{+} o_{t-1}^{U}$ & & & $-0.016(-2.172)^{* *}$ \\
$\Delta^{+} o_{t-2}^{U}$ & & & 0.176 \\
$\Delta^{+} o_{t-3}^{U}$ & & & 0.219 \\
$\Delta^{+} o_{t-4}^{U}$ & & & \\
\hline$R^{2}$ & 0.201 & & \\
\hline
\end{tabular}

Table 4: Parameter estimates from models with only oil price increases - Model 4, with only net oil price increases (NOPI, 12 quarters) - Model 5, and with only $\Delta^{+} o^{U}$ - Model 6. Intercept estimates not shown. T-statistics shown in parentheses. Significance at 10\%, 5\%, and 1\% denoted respectively by one, two, and three asterisks, calculated using critical values from 10, 000 bootstrap iterations. 


\begin{tabular}{|c|c|c|c|}
\hline \multicolumn{4}{|c|}{ Table 5. US GDP Growth Equation Estimates } \\
\hline & Model 7 & Model 8 & Model 9 \\
\hline \hline$\Delta y_{t-1}$ & $0.238(2.032)^{* *}$ & $0.229(2.552)^{* * *}$ & $0.162(1.335)$ \\
$\Delta y_{t-2}$ & $0.299(2.509)^{* * *}$ & $0.080(0.867)$ & $0.249(2.004)^{* *}$ \\
$\Delta y_{t-3}$ & $0.150(1.253)$ & $-0.019(-0.201)$ & $0.097(0.801)$ \\
$\Delta y_{t-4}$ & $0.012(0.103)$ & $-0.083(-0.920)$ & $-0.028(-0.238)$ \\
$\Delta^{+} o_{t-1}^{F}$ & $-0.007(-0.235)$ & & $-0.001(-0.030)$ \\
$\Delta^{+} o_{t-2}^{F}$ & $-0.044(-1.479)$ & & $-0.037(-1.189)$ \\
$\Delta^{+} o_{t-3}^{F}$ & $-0.022(-0.753)$ & & $-0.016(-0.525)$ \\
$\Delta^{+} o_{t-4}^{F}$ & $-0.030(-0.986)$ & & $-0.042(-1.323)$ \\
$\Delta^{-} o_{t-1}^{F}$ & $0.007(0.236)$ & & $0.009(0.283)$ \\
$\Delta^{-} o_{t-2}^{F}$ & $-0.059(-1.940)^{*}$ & & $-0.063(-1.896)^{*}$ \\
$\Delta^{-} o_{t-3}^{F}$ & $-0.047(-1.510)$ & & $-0.042(-1.242)$ \\
$\Delta^{-} o_{t-4}^{F}$ & $0.039(1.291)$ & & $0.036(1.122)$ \\
$\Delta^{+} o_{t-1}^{U}$ & & $-0.008(-1.022)$ & $-0.004(-0.498)$ \\
$\Delta^{+} o_{t-2}^{U}$ & & $-0.014(-1.873)^{*}$ & $-0.017(-2.192)^{* *}$ \\
$\Delta^{+} o_{t-3}^{U}$ & & $-0.006(-0.869)$ & $-0.009(-1.128)$ \\
$\Delta^{+} o_{t-4}^{U}$ & & $-0.016(-2.147)^{* *}$ & $-0.011(-1.379)$ \\
$\Delta^{-} o_{t-1}^{U}$ & & $-0.002(-0.234)$ & $-0.003(-0.342)$ \\
$\Delta^{-} o_{t-2}^{U}$ & & $0.016(1.617)$ & $0.014(1.446)$ \\
$\Delta^{-} o_{t-3}^{U}$ & & $0.007(0.764)$ & $0.007(0.740)$ \\
$\Delta^{-} o_{t-4}^{U}$ & & $0.007(0.718)$ & $0.003(0.294)$ \\
\hline$R^{2}$ & 0.235 & 0.199 & 0.295 \\
\hline & & & \\
\hline
\end{tabular}

Table 5: Parameter estimates from models given by allowing asymmetric responses of US GDP to changes in both oil price components - Model 9, and from models given by subsets of these regressors - Models 7 and 8. Intercept estimates not shown. T-statistics shown in parentheses. Significance at $10 \%, 5 \%$, and $1 \%$ denoted respectively by one, two, and three asterisks, calculated using critical values from 10,000 bootstrap iterations. 


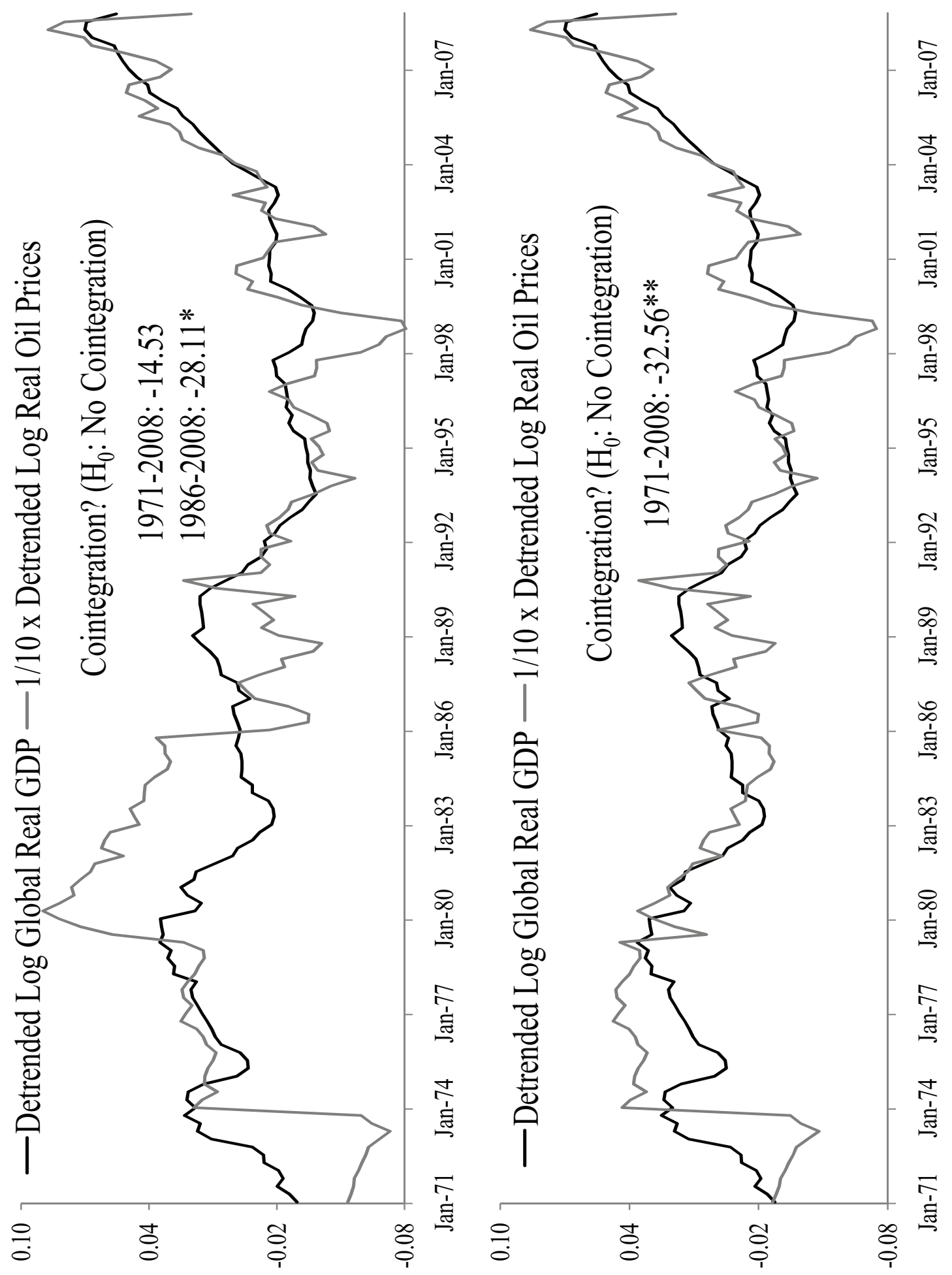

Figure 1: Log real oil prices and log global real GDP, detrended with a linear trend and a linear trend plus the 1979Q3-1985Q4 binary. One and two asterisks denote respectively 10\% and 5\% significance of Phillips-Ouliaris (1990) tests. 


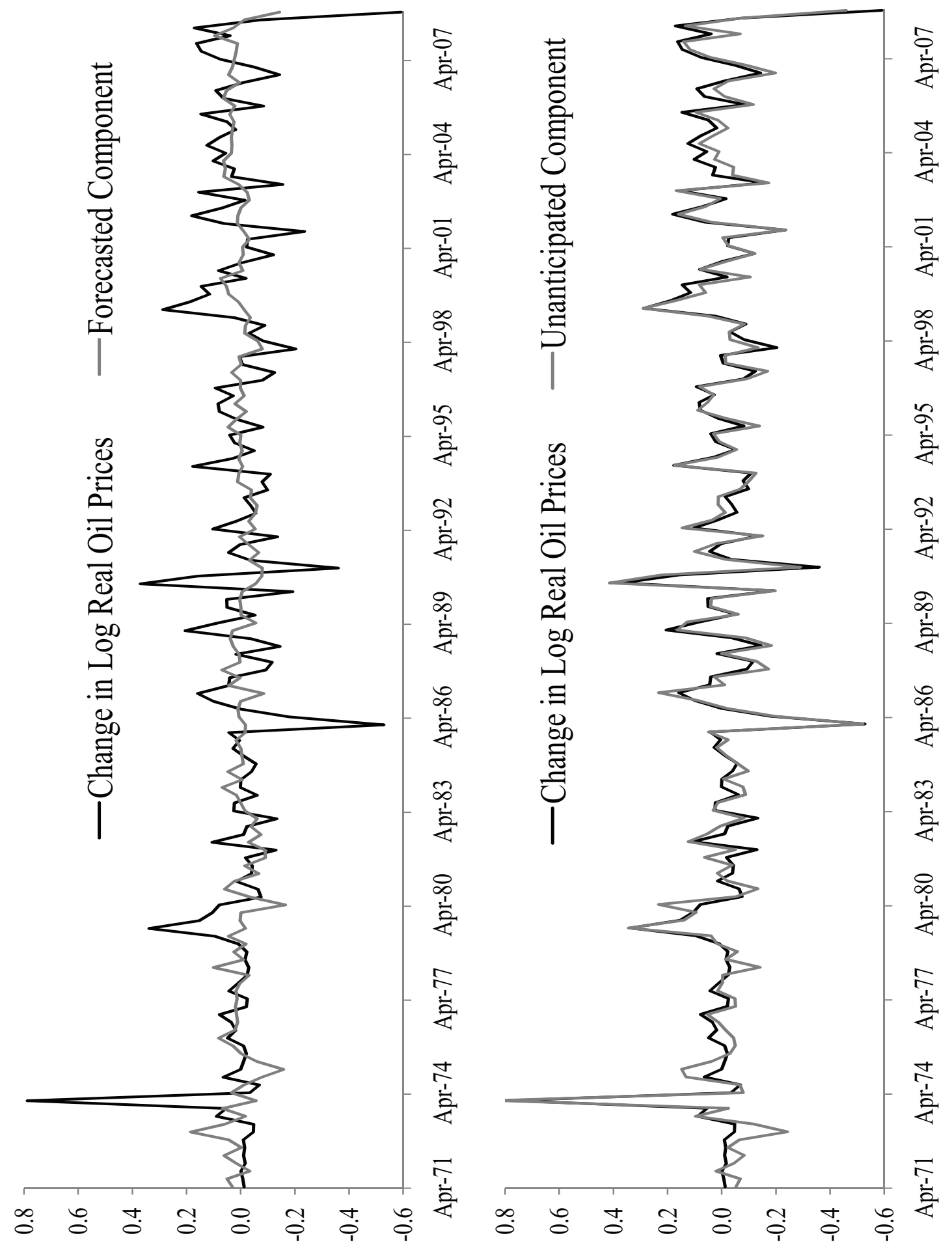

Figure 2: Decomposition of the first difference of log real oil prices into forecasted and unanticipated components. 


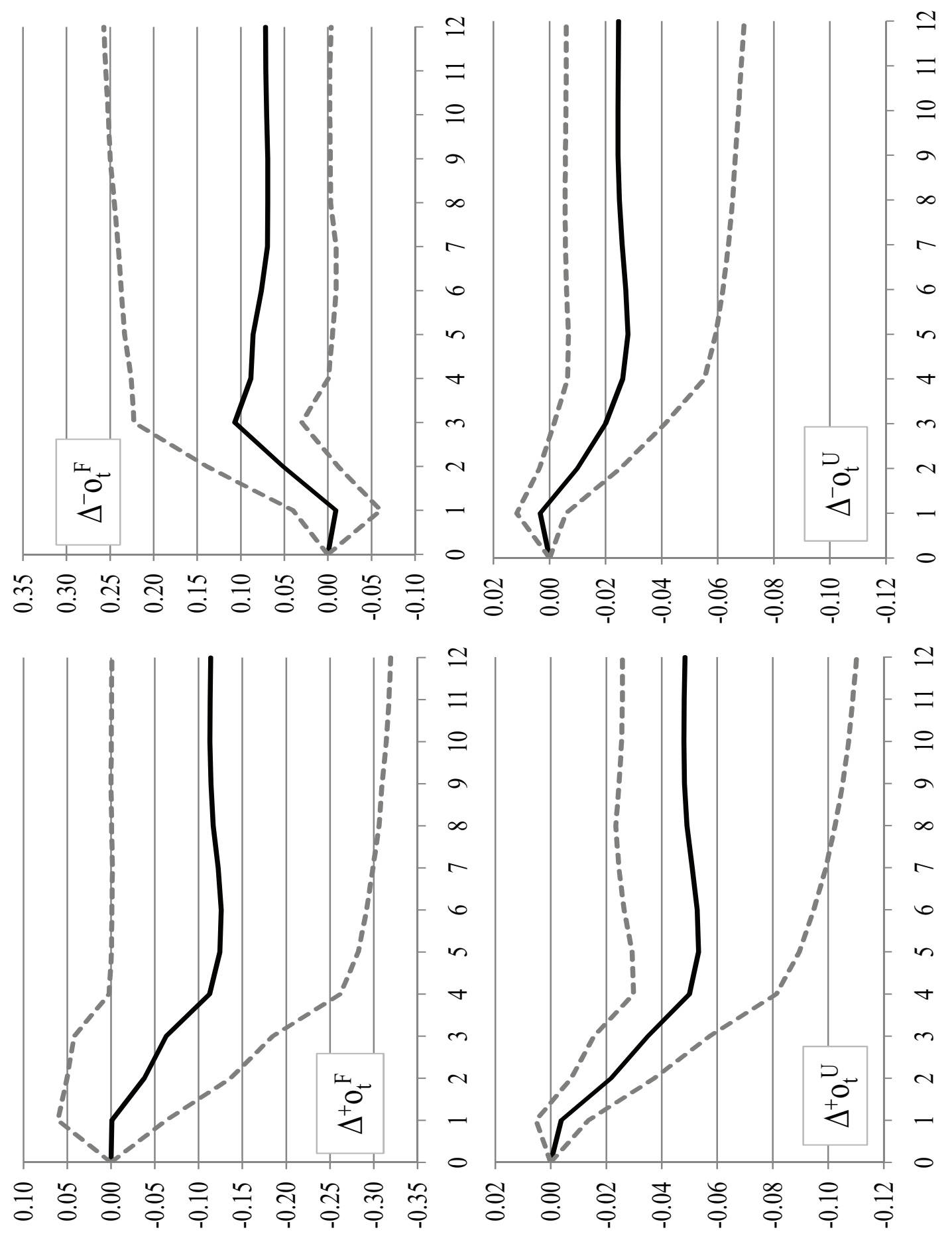

Figure 3: Cumulative conditional responses to unit increases in $\Delta^{+} o_{t}^{F}, \Delta^{+} o_{t}^{U}$ and unit decreases in $\Delta^{-} o_{t}^{F}, \Delta^{-} o_{t}^{U}$, holding the other components constant and orthogonalized with respect to GDP. $5 \%$ and $95 \%$ quantiles shown, constructed using 10,000 bootstrap iterations. See Appendix B. 


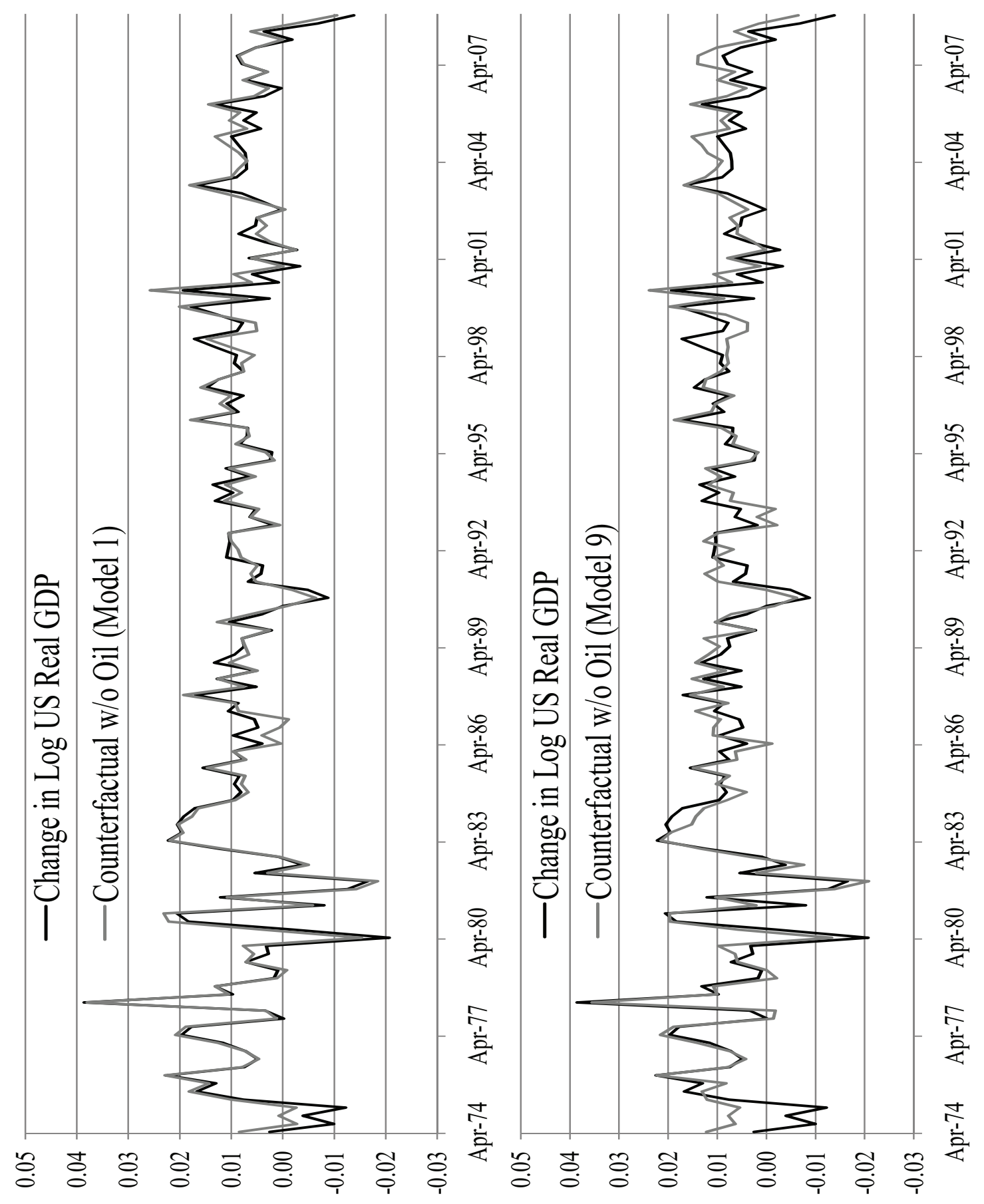

Figure 4: Actual US GDP growth rates compared to counterfactual US GDP growth rates with no stochastic oil fluctuations. (a) Counterfactual calculated by subtracting the oil component of Model 1, orthogonalized with respect to GDP. (b) Counterfactual calculated by subtracting all oil components of Model 9, orthogonalized with respect to GDP. See Appendix B. 


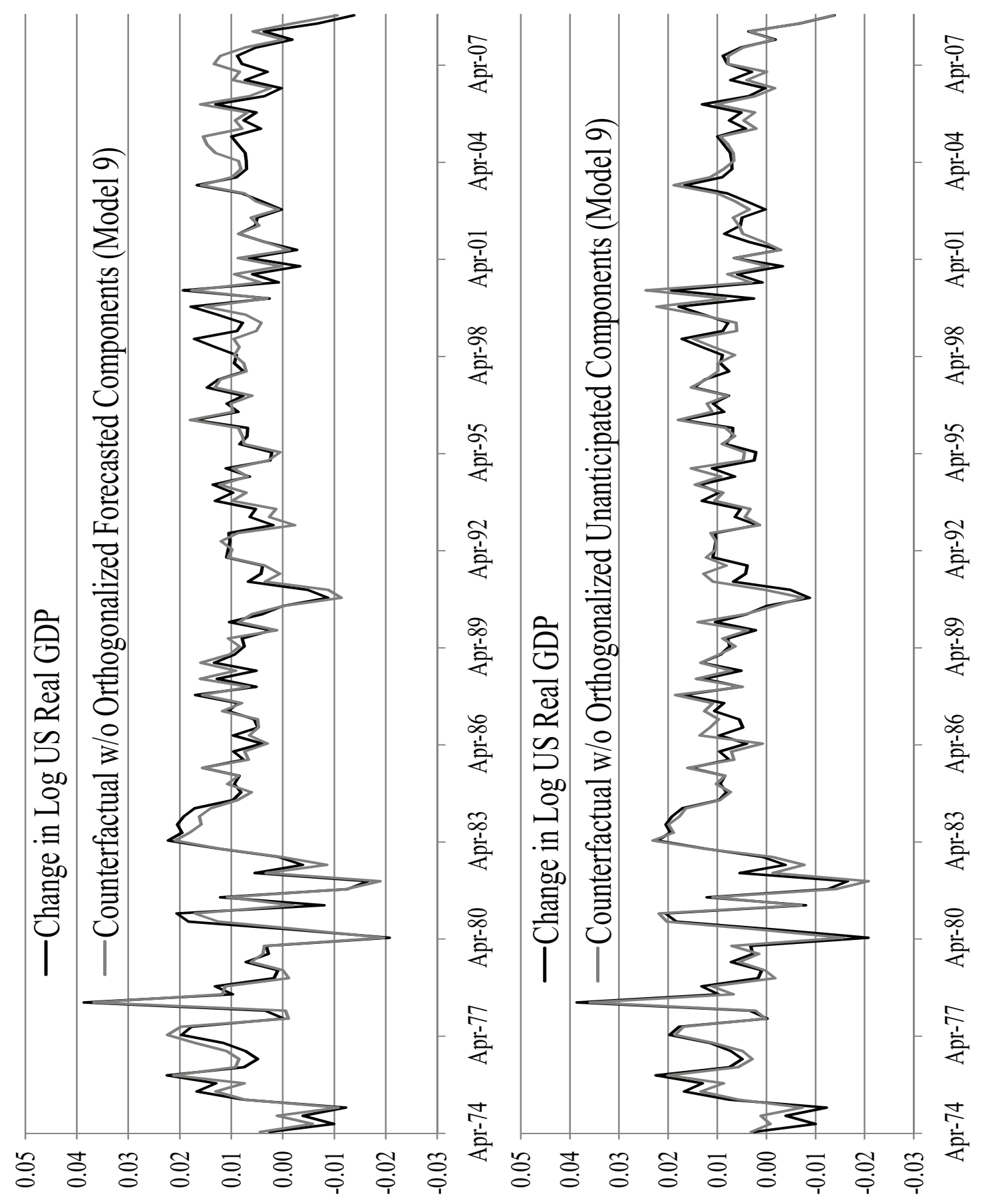

Figure 5: Actual US GDP growth rates compared to counterfactual US GDP growth rates. (a) No forecasted stochastic components in Model 9. Counterfactual calculated by subtracting forecasted stochastic components (positive and negative changes), orthogonalized with respect to GDP and unanticipated components (positive and negative changes). (b) No unanticipated components in Model 9. Counterfactual calculated by subtracting unanticipated components (positive and negative changes), orthogonalized with respect to GDP and stochastic forecasted components (positive and negative changes). See Appendix B. 